\title{
INFLUENCE OF CROP GROWTH AND WEATHER CONDITIONS ON SPECKLED LEAF BLOTCH IN WINTER WHEAT
}

\author{
T. ARMOUR, S.L.H. VILJANEN-ROLLINSON, S.F. CHNG, R.C. \\ BUTLER, M.G. CROMEY, P.D. JAMIESON and R.F. ZYSKOWSKI \\ Crop \& Food Research, Private Bag 4704, Christchurch \\ Corresponding author: armourt@crop.cri.nz.
}

\begin{abstract}
Speckled leaf blotch (SLB), a foliar disease of winter wheat, caused by Septoria tritici (teleomorph Mycosphaerella graminicola) can cause significant yield losses. Wheat crops are at greatest risk during stem extension, when the final three leaves emerge in close proximity to infected leaves lower in the canopy. Winter wheat cv. Consort was sown in May 2002, to test a model that links development of SLB in the field to weather events, and to compare disease severity between plots treated with fungicide applied at three different crop growth stages. Generally quite low disease levels were experienced, associated with a small number of likely infection events. This meant that the top three leaves were infected after they were fully emerged, and SLB severity was low, as there was little time for secondary cycles to occur before the leaves senesced. Despite low disease severity, there was a significant yield response to applied fungicide, increasing with the number of applications. The model requires some improvement.
\end{abstract}

Keywords: speckled leaf blotch, wheat, Mycosphaerella graminicola, Septoria tritici, modelling.

\section{INTRODUCTION}

Speckled leaf blotch (SLB) is a foliar disease of winter wheat that causes major yield losses in the United Kingdom (Hardwick et al. 2001), especially when it becomes severe on the final three leaves of plants (Thomas et al. 1989). Infection of winter wheat crops by Mycosphaerella graminicola (Fückel) J. Schrot. occurs in the autumn and winter from ascospores released from stubble of previous wheat crops (Shaw \& Royle 1989). Secondary spread within crop canopies by pycnidia of Septoria tritici Roberge in Desmaz., occurs during stem extension and is aided by rain splash (Shaw \& Royle 1993). In the UK, there is a focus on developing weather-based models to assist with fungicide timings for control of SLB. In New Zealand, the disease has become more pronounced with the introduction of susceptible cultivars of English origin, in combination with earlier sowing dates. Fungicide applications based on preset crop growth stages are used to control the disease. However, weather conditions are critical for disease spread within crop canopies, and are often overlooked.

The aims of this project were to test a model that links development of SLB in the field to weather events, and to compare disease severity between plots treated with fungicide applied at three different crop growth stages or according to the model. From this we hope to develop fungicide guidelines that maximise efficacy and minimise fungicide use.

\section{MATERIALS AND METHODS}

Winter wheat cv. Consort was sown in $4 \mathrm{~m}$ long replicated field plots (six rows at $20 \mathrm{~cm}$ spacings) at Lincoln, Canterbury, on 30 May 2002. There were six fungicide 
timing treatments, with triple replicates of untreated plots, replicated four times in a randomised block design. Buffer plots of cv. Consort surrounded the trial. The trial area had $150 \mathrm{~kg} /$ ha urea (46\% Nitrogen) applied on 19 September. A post-emergence herbicide was applied to control weeds on 23 September, and the trial area was irrigated $(35 \mathrm{~mm})$ on 24 October, 6 November and 16 December.

The fungicide treatments were chosen to allow monitoring of disease progress at different stages of crop development. Untreated plots and a calendar treatment allowed unchecked disease development and disease-free crop growth to occur. Fungicide treatments and application dates are described in Table 1. Epoxiconazole (125 g a.i./litre; Opus®) and azoxystrobin (250 g a.i./litre; Amistar®) were applied with a motorised knapsack sprayer according to the dates in Table 1. Each chemical was applied at a quarter of the recommended rate, except for the model treatment, where a lower rate (15.6 $\mathrm{g}$ a.i./litre) of epoxiconazole was used for the second application. This rate was reduced as it was assumed that less eradicant activity was required.

\section{TABLE 1: Fungicide treatment descriptions and application dates.}

\begin{tabular}{lll}
\hline Treatment & Description & Date applied (2002) \\
\hline $\begin{array}{l}\text { 1. Untreated } \\
\text { 2.Calendar }\end{array}$ & $\begin{array}{l}\text { No fungicide applied } \\
\text { 3 week fungicide application programme } \\
\text { commenced at growth stage (GS) 30 }\end{array}$ & $\begin{array}{l}30 / 09,19 / 10,5 / 11, \\
\text { (Zadoks et al. 1974) }\end{array}$ \\
3. Model & $\begin{array}{l}\text { Weather-based decision model commenced } \\
\text { at GS 30 }\end{array}$ & $5 / 11,12 / 12$ \\
4. Single & $\begin{array}{l}\text { At full emergence of leaf 3 } \\
\text { (L3, approx. GS 32). }\end{array}$ & $30 / 10$ \\
5. Double & $\begin{array}{l}\text { At full emergence of L3 and flag leaf } \\
\text { (FL, GS 39) }\end{array}$ & $30 / 10,23 / 11$ \\
6. Triple & $\begin{array}{l}\text { Conventional programme. At full emergence } \\
\text { of L3, FL and mid-flower (GS 65) }\end{array}$ & $30 / 10,23 / 11,12 / 12$ \\
&
\end{tabular}

For the model, it was assumed that infection will occur in the presence of inoculum and if there is $5 \mathrm{~mm}$ or more of rainfall or irrigation in one day or $10 \mathrm{~mm}$ or greater over three consecutive days (minimum of $1 \mathrm{~mm}$ a day) (Thomas et al. 1989), where the temperature on the following night exceeds $5^{\circ} \mathrm{C}$ (X. Bailleau, pers. comm.). Fungicide was applied when a trigger event occurred. Weather assessments recommenced 21 days after the first fungicide application, and continued until GS 75. Daily rainfall and maximum and minimum temperature data were regularly downloaded from the Lincoln meteorological station, approximately $1 \mathrm{~km}$ from the trial site.

An estimated latent period from the UK of $250-300$ degree days $\left({ }^{\circ} \mathrm{Cd}\right)$ with a base temperature of $-2^{\circ} \mathrm{C}$ (D. Lovell, unpubl. data) was assumed between infection and appearance of pycnidia. The date when the mean disease level rose above $0 \%$ was used as the date when pycnidia were first visible, from which the latent period was subtracted to identify periods of infection.

Disease severity (\%) and the percentage of green leaf area (\% GLA) of the top three leaves were visually assessed for each leaf from 10 randomly chosen tillers per plot at 7-10 day intervals. Scoring commenced when each leaf was fully emerged (ligule visible) and continued until canopy senescence. Severity was scored as the proportion of leaf area covered by lesions with visible pycnidia. GLA was assessed to monitor leaf emergence and senescence. Observations were made to identify the dates that tips of each leaf layer emerged. These dates were scored as 0\% GLA, and were added to the $\%$ GLA measurements so that infection periods could be monitored over the entire development of each leaf layer. Leaves were scored from the top of the tiller down, with the flag leaf (FL) recorded as the top leaf and the penultimate leaf as L2, and L3 the one below. During stem elongation, tillers from the buffer plots were dissected to identify growth stages, and the final leaf position and relative emergence of individual leaves. 
The trial was harvested on 14 February 2003 with a plot harvester. Grain yield (kg/plot) was measured and expressed as t/ha at $14 \%$ moisture content.

Disease severity and \% GLA means were calculated for each leaf layer. Plots where more than $80 \%$ of leaves had died were excluded from the severity data before the means were calculated so as to reduce bias in estimated infection levels. The data were analysed using analysis of variance (data other than means is not presented). The effect of fungicide treatments on yield was analysed using analysis of variance with GenStat for Windows ( $6^{\text {th }}$ Edition).

\section{Disease development}

\section{RESULTS}

The final three leaves on plants in each treatment were fully emerged before infection occurred. At first, visible disease was slow to develop. This was followed by a rapid increase that ceased as the infected leaves died. SLB developed on L2 and L3 earlier on plants in untreated plots than in fungicide-treated plots. The flag leaf (FL) showed visible symptoms of disease at approximately the same time for all treatments, except for the triple treatment where disease was not observed on the final two leaves. Disease severity, first observations of pycnidia and the estimated infection period are indicated for each leaf in Figure 1 for each fungicide treatment, except treatment 2 (Calendar) due to the lack of disease symptom development.

\section{Fungicide treatments}

Maximum disease severity on the top three leaves was greatest on plants in the untreated plots, with severity on L3 being the greatest with $17 \%$ of the leaf infected (Fig. 1). Of the five treatments receiving fungicide, the single application had the greatest mean severity on the top three leaves. The plants in plots where a single treatment was applied to L3 became infected later, and had less disease, than occurred in the untreated plots, although severity on the top two leaves reached similar levels without further application.

A second application at FL (double and triple treatments) protected L2 and FL of plants. Traces of disease were found on the top two leaves of the double treatment, but disease did not increase in severity. A third fungicide applied at anthesis prevented the development of any visible disease on L2 and FL.

The model treatment received two fungicide applications after weather conditions occurred that met the model criteria. L2 had just fully emerged when the first application was applied. The second fungicide application occurred 33 days later at anthesis. The FL emerged during the 21-day period of fungicide protection following the first application. Severity was lower on the top three leaves than the single application, but higher on L2 and FL than the double or triple treatments.

\section{Harvest data}

All fungicide treatments led to improved yields $(\mathrm{P}<0.05)$ over the untreated plots by more than $0.9 \mathrm{t} / \mathrm{ha}$ (Table 2$)$. Yield was greater $(\mathrm{P}<0.05)$ for the double treatment than for the single or model treatments (by approximately $1 \mathrm{t} / \mathrm{ha}$ ). The highest yields were obtained by the double and triple treatments where fungicide was applied to the FL.

TABLE 2: Mean grain yields (t/ha at $14 \%$ moisture) from plots to which different fungicide treatments were applied.

\begin{tabular}{lc}
\hline Treatment & Yield \\
\hline Untreated & 11.22 \\
Calendar & 12.75 \\
Model & 12.13 \\
Single application & 12.14 \\
Double application & 13.15 \\
Triple application & 12.83 \\
LSD (P<0.05, df=21) to compare: & 0.73 \\
any treated with untreated & 0.89 \\
any two treated & \\
\hline
\end{tabular}




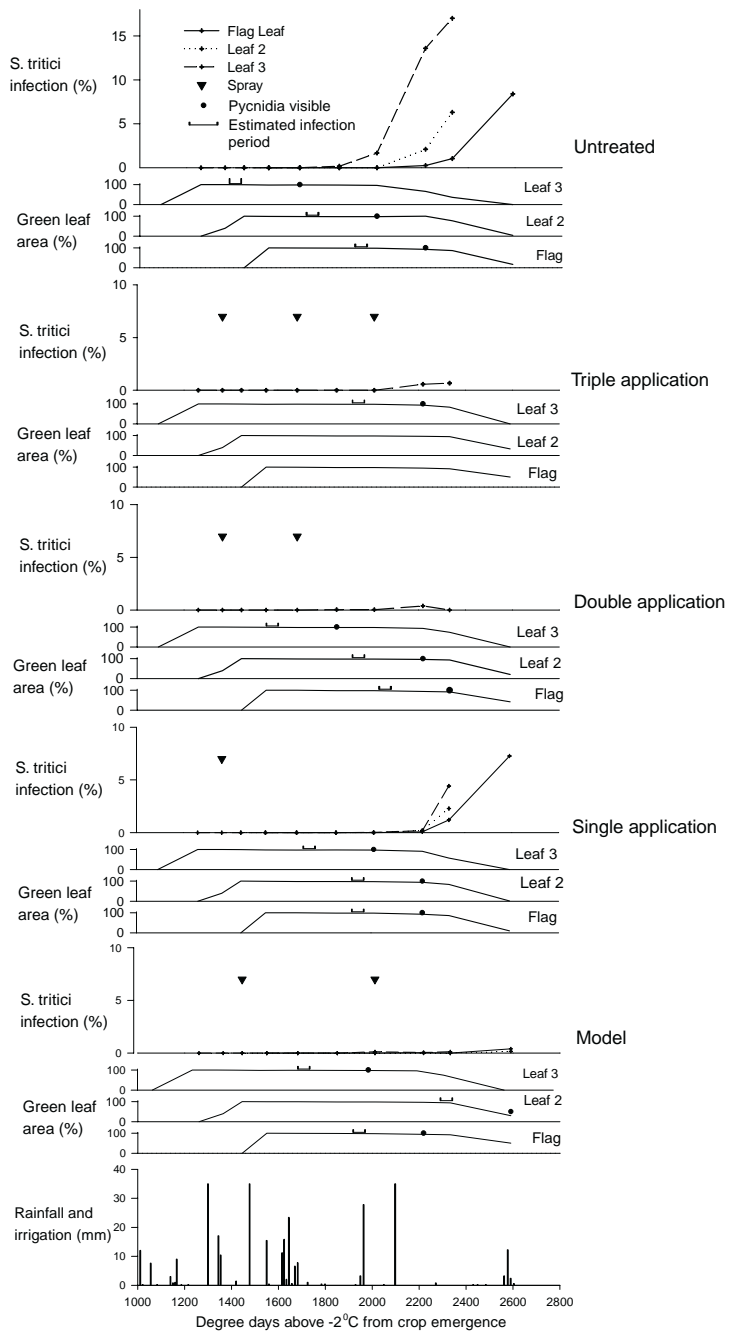

FIGURE 1: Disease severity, leaf area, first observations of pycnidia and estimated infection period for five fungicide treatments on the top three leaves of wheat cv. Consort. Symbols on disease severity graphs indicate assessment times. Percentage GLA and the proportion of leaf emerged during leaf expansion are shown, along with rainfall and irrigation data.

\section{DISCUSSION}

Disease occurrence and development in the upper three leaves was low, even in the unsprayed treatment. Despite the low severity, disease still decreased as more fungicide applications were added to the programme. Even in the unsprayed plots, disease was not 
evident on L3 until the FL had completely emerged. According to model criteria, this meant that infection did not occur until L3 was completely emerged.

Shaw \& Royle (1993) considered that the effect of early infection is to increase the opportunity for secondary cycles of infection and multiplication. In our experiment, late infection meant that severity remained low because there was less time for the disease to multiply before senescence occurred. Late infection suggests that conditions suitable for infection did not occur as the tips were emerging. According to the model criteria used, suitable trigger events did not occur until L2 was expanding. However, the time of disease appearance on L3 suggests infection did occur before these trigger events. This implies that the assumed latent period may not be correct in New Zealand conditions, although there may have been some problems in identifying the time of disease appearance, because our observations were not sufficiently frequent to pinpoint the day of appearance.

Disease did not occur, or severity was much lower, on leaves treated with fungicide because fungicide delayed the onset of disease, and reduced the time for secondary cycles to occur before senescence. In the model treatment application decisions were based solely on weather conditions, and ignored crop development. Hence the FL became infected because it emerged after the first fungicide application and was exposed to an infection event. The second fungicide application at anthesis occurred when the disease was in the latent phase on the FL and the fungicide was unable to eradicate the disease. A lower rate of epoxiconazole was used because it was assumed that less eradicant activity would be needed, as the infection would have only just occurred. However, in both cases, the application was delayed by unsuitable conditions. A low rate of systemic fungicide may not be appropriate for applications based on trigger events, as it is not always possible to apply fungicide to the crop immediately.

The top three leaves of plants in wheat crops are important contributors to yield and any loss of leaf area can result in yield losses (Thomas et al. 1989). The most effective treatments with the lowest visible severity and highest yields were the double, triple and calendar applications. The double treatment had slightly more disease than the triple and calendar treatments, but achieved similar yields at reduced cost.

Testing of the weather-based model was inconclusive because of the low disease incidence. However, some questions about the length of the latent period were raised, and this requires more precise definition using carefully targeted experiments. If these deficiencies can be addressed, then there are good prospects of maximising efficacy and minimising fungicide use for control of SLB in wheat crops by using a model that explicitly connects disease and crop development through the effects of weather on both.

\section{ACKNOWLEDGEMENTS}

Funding for this research was provided by the New Zealand Foundation for Research, Science and Technology and the Foundation for Arable Research. We thank Cathy Munro for sowing and harvesting the trial, and Ros Lister and Anna Mills for helping with data collection.

\section{REFERENCES}

Hardwick, N.V.; Jones, D.R.; Slough, J.E. 2001: Factors affecting diseases of winter wheat in England and Wales, 1989-98. Plant Path. 50: 453-462.

Shaw, M.W.; Royle, D.J. 1989: Airborne inoculum as a major source of Septoria tritici (Mycosphaerella graminicola) infections in winter wheat crops in the UK. Plant Path. 38: 35-43.

Shaw, M.W.; Royle, D.J. 1993: Factors determining the severity of epidemics of Mycosphaerella graminicola (Septoria tritici) on winter wheat in the UK. Plant Path. 42: 882-899.

Thomas, M.R.; Cook, R.J.; King, J.E. 1989: Factors affecting development of Septoria tritici in winter wheat and its effect on yield. Plant Path. 38: 246-257.

Zadoks, J.C.; Chang, T.T.; Konzak, C.F. 1974: A decimal code for growth stages of cereals. Weed Res. 14: 415-421. 